\title{
Biosynthesis of a Mycobacterial Lipopolysaccharide
}

\author{
INCORPORATION OF [ $\left[{ }^{14} \mathrm{C}\right] A C Y L$ GROUPS BY WHOLE CELLS IN VIVO
}

\author{
By KOYU NARUMI, JOHN M. KELLER and CLINTON E. BALLOU* \\ Department of Biochemistry, University of California, Berkeley, Calif. 94720, U.S.A.
}

(Received 9 October 1972)

\begin{abstract}
1. Mycobacterium phlei (A.T.C.C. 356) cells were incubated with ${ }^{14} \mathrm{C}$-labelled short-chain fatty acids and the 6-O-methylglucose-containing lipopolysaccharides that became esterified with radioactive acyl groups were isolated. The pattern of labelling of these lipopolysaccharides with the different acyl groups, the effects of different conditions on labelling patterns, and the kinetics of the turnover of ${ }^{14} \mathrm{C}$-labelled acyl groups were studied. 2. The labelling patterns are summarized as follows. $\left[1-{ }^{14} \mathrm{C}\right]$ Acetate was incorporated into all of the acyl groups. $\left[1-{ }^{14} \mathrm{C}\right]$ Propionate led to labelling of propionate and succinate, while $\left[1-{ }^{14} \mathrm{C}\right]$ isobutyrate was incorporated mostly as such, along with a trace amount in iso-octanoate. 3 . Under the conditions of the experiments, $\left[1-{ }^{14} \mathrm{C}\right]$ acetate was rapidly incorporated into succinyl (3-carboxypropionyl) and octanoyl groups, whereas the acetyl groups themselves were labelled more slowly. Radioactivity in propionyl and succinyl groups, originating from $\left[1-{ }^{14} \mathrm{C}\right]$ propionate, attained maximum values and then gradually decreased in both. Incorporation of $\left[1-{ }^{14} \mathrm{C}\right]$ isobutyrate proceeded slowly but reached a plateau and remained constant. While $n$-butyrate is not a normal constituent of methylglucose-containing lipopolysaccharides, it was incorporated as such when $n-\left[11^{14} \mathrm{C}\right]-$ butyrate was supplied in the medium. $4 .\left[1-{ }^{14} \mathrm{C}\right]$ Acetyl groups were readily displaced by unlabelled acetate. On the other hand, the specific radioactivity of the succinyl group continued to increase during a $3 \mathrm{~h}$ incubation with unlabelled succinate. Propionyl and succinyl groups, labelled by $\left[1-{ }^{14} \mathrm{C}\right]$ propionate, were displaced slowly by unlabelled propionate or succcinate. The isobutyryl group of the lipopolysaccharides did not turn over, in contrast to the results obtained with the other acyl substituents.
\end{abstract}

The methylglucose-containing lipopolysaccharide of Mycobacterium species (Ballou, 1968) has a molecular weight of about 3500 and is a soluble component of the cell cytoplasm. At the same time, it possesses moderate lipophilic properties as a consequence of the methylation in position 6 of 10 of the 18 glucose residues in the polysaccharide and the esterification of this partially methylated polysaccharide with $6-9 \mathrm{~mol}$ of short-chain fatty acids. The methylglucose-containing lipopolysaccharide can be resolved by chromatography on DEAE-Sephadex into four species that differ in the content of monoesterified succinic acid, but each of these contains approximately the same complement of the other acyl groups (acetate, propionate, isobutyrate and octanoate). The general structure is shown in Fig. 1.

Because of the unusual assortment of short-chain fatty acids in the methylglucose-containing lipopolysaccharide and its localization in the cell cytoplasm, we have considered the possibility that it might function as an acyl carrier in fatty acid synthesis. To test this hypothesis, we have investigated the metabolism of several of the lipopolysaccharide species by whole

* To whom inquiries should be sent. cells. Although the results of this study show that each acyl group has its own characteristic rate of incorporation and turnover, we found no evidence that the lipopolysaccharide is primarily involved as a donor for the synthesis of long-chain fatty acids.

\section{Materials and Methods}

\section{Materials}

The following radioactive materials were used: sodium $\left[1{ }^{14} \mathrm{C}\right]$ acetate, $23 \mathrm{Ci} / \mathrm{mol}$ (Calbiochem, Los Angeles, Calif., U.S.A.), and $57 \mathrm{Ci} / \mathrm{mol}$ (Schwarz Bioresearch Inc., Orangeburg, N.Y., U.S.A.); sodium $\left[1-{ }^{14} \mathrm{C}\right]$ propionate, $3 \mathrm{Ci} / \mathrm{mol}$ (New England Nuclear Corporation, Boston, Mass., U.S.A.); sodium $\left[1 .{ }^{14} \mathrm{C}\right]$ isobutyrate, $7.5 \mathrm{Ci} / \mathrm{mol}$ (The Radiochemical Centre, Amersham, Bucks., U.K.); sodium $n$ - $\left[1-{ }^{14} \mathrm{C}\right]$ butyrate, $15 \mathrm{Ci} / \mathrm{mol}$, and sodium $\left[1-{ }^{14} \mathrm{C}\right]-$ hexanoate, $15.2 \mathrm{Ci} / \mathrm{mol}$ (Nuclear-Chicago, Des Plaines, Ill., U.S.A.); sodium $\left[1{ }^{14} \mathrm{C}\right]$ octanoate, $2 \mathrm{Ci} / \mathrm{mol}$ (New England Nuclear Corporation).

Sephadex G-25 (fine), Sephadex G-50 (fine) and DEAE-Sephadex A-25 (medium) vere obtained from

Vol. 132 


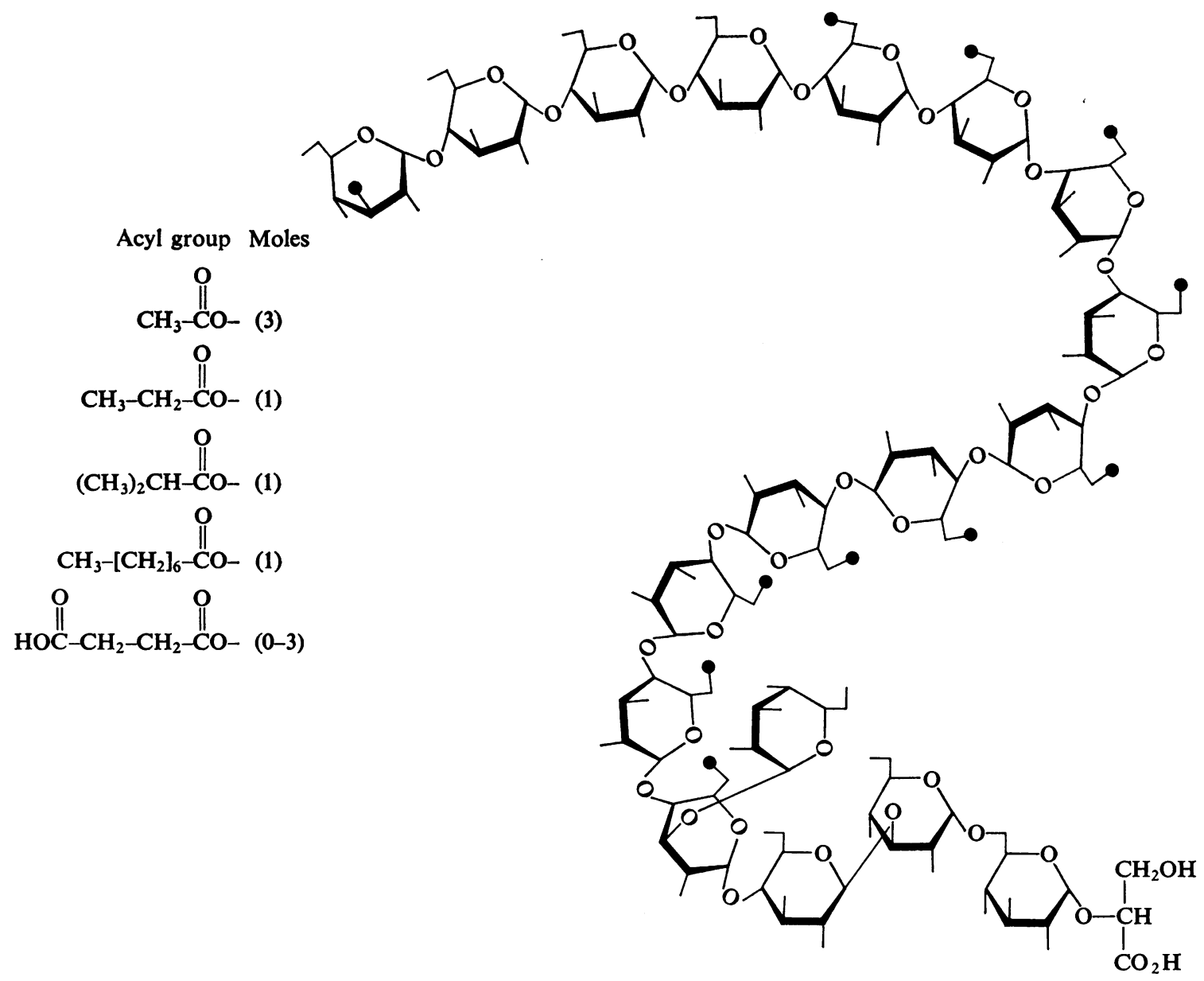

Fig. 1. Structure of the methylglucose-containing lipopolysaccharide of Mycobacterium species

The closed circles on the polysaccharide part indicate the positions of methylation. The acyl groups are esterified to hydroxyl groups on the polysaccharide, the positions of which are not specified.

Pharmacia, Piscataway, N.J., U.S.A., and Dowex AG-501 mixed-bed resin came from Bio-Rad, Richmond, Calif., U.S.A.

\section{Methods}

Analytical methods. Carbohydrate was assayed by the phenol-sulphuric acid method (Smith \& Montgomery, 1956), with D-glucose as the standard in the determination of glucose, 6-O-methylglucose and 3-O-methylglucose. Paper chromatograms were developed in descending fashion on Whatman no. 1 filter paper. The solvent systems used were (compositions by volume): solvent 1 , butan-1-ol-pyridinewater $(10: 3: 3)$; solvent 2 , propan-2-ol-7 $\mathrm{M}-\mathrm{NH}_{3}$ (3:1); solvent 3 , benzene-formic acid-water $(1: 1: 1$, upper layer). Reference acyl hydroxamates for paper chromatography were synthesized by standard methods (Keller \& Ballou, 1968). Gas chromatography was done using a $1.52 \mathrm{~m}(5 \mathrm{ft})$ column of $10 \%$ FFAP on 100-200 mesh Chromosorb W (Varian Associates) with a $\mathrm{N}_{2}$ flow of $20 \mathrm{ml} / \mathrm{min}$.

Radioactivity was determined by scintillation counting in $10 \mathrm{ml}$ of Bray's (1960) dioxan solution. Efficiency for ${ }^{14} \mathrm{C}$ was $57 \%$, and quenching caused by addition of $0.1 \mathrm{ml}$ of water or $0.15 \mathrm{M}-\mathrm{NH}_{4} \mathrm{HCO}_{3}$ was $1 \%$. Radioactivity on paper chromatograms was determined with a Vanguard Chromatogram Scanner or by counting $1 \mathrm{~cm}$ strips in Bray's (1960) solution. Specific radioactivity of the methylglucose-containing lipopolysaccharide is expressed as c.p.m./ $\mu \mathrm{mol}$ of lipopolysaccharide, and that of acyl groups as 
c.p.m./ $/ \mathrm{mol}$ of acyl group in the lipopolysaccharide. Thus, it should be kept in mind that all methylglucosecontaining lipopolysaccharide species have three acetyl groups while the fractions of methylglucosecontaining lipopolysaccharide (MGLP-II, -III and -IV) have different amounts of succinate.

Turnover experiments. Turnover experiments with unlabelled fatty acids were performed in two ways. In one experiment, the sodium salt of the fatty acid (1000 times the amount of radioactive substance originally present) was added to the cell suspension and the incubation was continued with no interruption at $30^{\circ} \mathrm{C}$ with shaking. In the other experiments, cells were collected after incubation, washed once with cooled medium, resuspended in fresh medium and incubated with unlabelled fatty acid at a concentration 100 times that of the $\left[{ }^{14} \mathrm{C}\right]$ fatty acid.

Isolation and fractionation of the methylglucosecontaining lipopolysaccharide. Methods for the extraction (Brennan \& Ballou, 1967) and fractionation (Keller \& Ballou, 1968) of the methylglucose-containing lipopolysaccharide were modified as follows. Wet packed cells were extracted twice with acetone. The acetone-dried cells were refluxed twice with $70 \%$ aq. ethanol for $2 \mathrm{~h}$, and the extracts were evaporated to dryness below $40^{\circ} \mathrm{C}$ on a rotary evaporator. The residue thus obtained was distributed between the layers of a chloroform-methanol-water mixture $(8: 4: 3$, by vol.). The upper layer of the solvent mixture was separated and freeze-dried, and the residue was passed through a Sephadex G-25 column $(2 \mathrm{~cm} \times 195 \mathrm{~cm})$ in $0.1 \mathrm{M}$-acetic acid. A radioactive fraction, which contained the methylglucose-containing lipopolysaccharide, was eluted near the void volume (Fig. $2 a$ ). It was freeze-dried and purified further by chromatography on a Sephadex G-50 column $(2 \mathrm{~cm} \times 195 \mathrm{~cm})$ (Fig. $2 b)$. The radioactive lipopolysaccharide fraction, which slightly preceded the main carbohydrate peak, was freeze-dried and dissolved in a small amount of chloroform-methanol $(2: 1, v / v)$. The clear supernatant, obtained by centrifugation, was evaporated and the residue was fractionated on a column $(1 \mathrm{~cm} \times 30 \mathrm{~cm})$ of DEAESephadex A-25 ( $\mathrm{HCO}_{3}-$ form) with a linear gradient from water to $0.15 \mathrm{M}-\mathrm{NH}_{4} \mathrm{HCO}_{3}$ at $4^{\circ} \mathrm{C}$ (Fig. $2 c$ ). Each lipopolysaccharide fraction thus eluted was freeze-dried and desalted by Sephadex G-25 column chromatography in water.

Possible contamination of the fractions by lipopolysaccharide-like materials was checked as a routine by paper chromatography of acid hydrolysates in solvent 1. Re-extraction of methylglucose-containing lipopolysaccharide with chloroform-methanol (2:1, $\mathrm{v} / \mathrm{v}$ ), before the DEAE-Sephadex step, was indispensable for isolation of pure methylglucose-containing lipopolysaccharide, otherwise ${ }^{14} \mathrm{C}$-labelled succinylated polymannosides with the same size and charge as the lipopolysaccharide usually contaminated the final preparations. Sometimes purification was accomplished by extracting the dried $70 \%$ ethanol extract with chloroform-methanol $(2: 1, \mathrm{v} / \mathrm{v})$ and then subjecting the material that was soluble in this solvent to distribution between the two layers of a chloroform-methanol-water mixture $(8: 4: 3$, by vol.). That the radioactivity of the methylglucosecontaining lipopolysaccharide was exclusively present

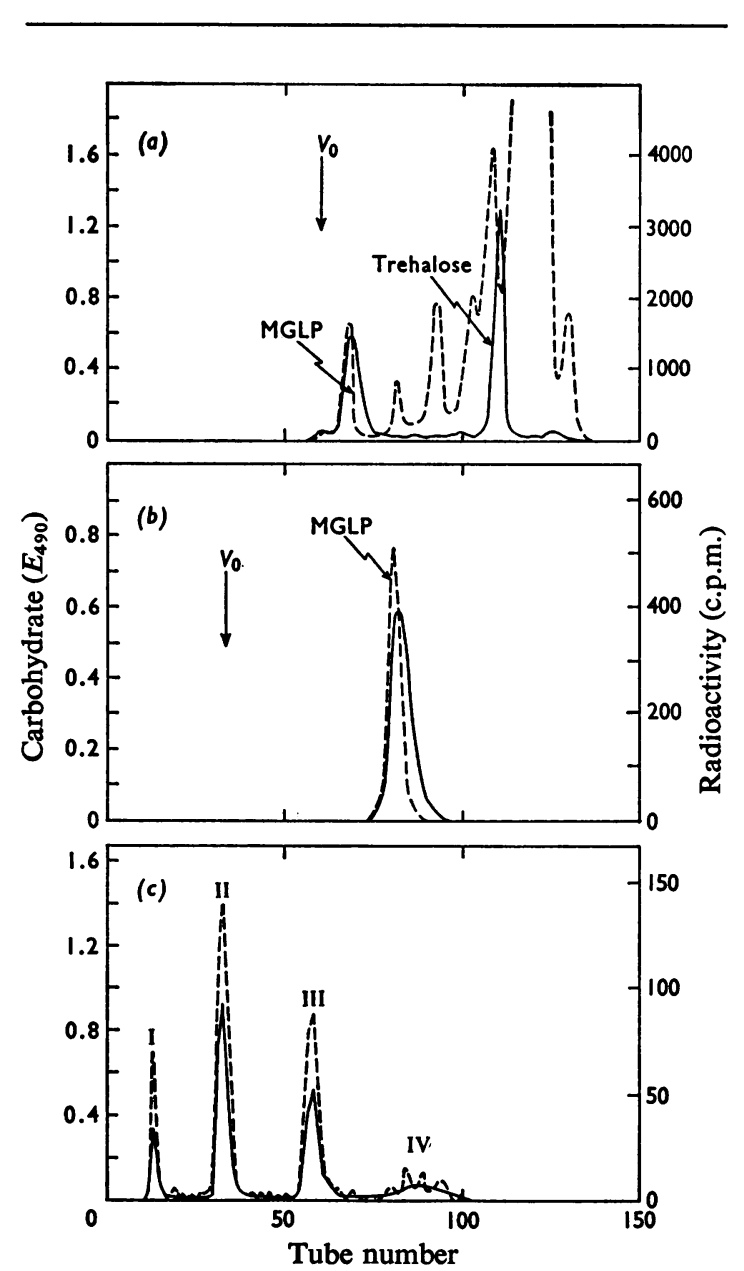

Fig. 2. Purification of ${ }^{14} \mathrm{C}$-labelled methylglucosecontaining lipopolysaccharide

(a) Chromatography on a Sephadex G-25 column; (b) rechromatography of the methylglucose-containing lipopolysaccharide peak (MGLP) from $(a)$ on a Sephadex G-50 column; (c) chromatography of the methylglucose-containing lipopolysaccharide fraction from $(b)$ on DEAE-Sephadex. The roman numerals in (c) stand for fractions MGLP-I, -II, -III, and -IV. $V_{0}$ is the void volume. - $-E_{490} ;---$, radioactivity. 
in the acyl groups was proved by the isolation of non-radioactive polysaccharide after saponification.

Formation, separation and assay of radioactive acyl hydroxamates. Radioactive methylglucose-containing lipopolysaccharide (1-2mg) was dissolved in $0.02 \mathrm{ml}$ of water and $0.02 \mathrm{ml}$ of $3.5 \mathrm{M}$-alkaline hydroxylamine, which was freshly prepared by mixing $1 \mathrm{ml}$ of $3.5 \mathrm{M}-\mathrm{NaOH}$ and $1 \mathrm{ml}$ of $2 \mathrm{M}-\mathrm{NH}_{2} \mathrm{OH}, \mathrm{HCl}$. After reaction at room temperature for $20 \mathrm{~min}, 0.5 \mathrm{ml}$ of methanol was added and the white precipitate of salt that formed was removed by centrifugation. The supernatant was decationized by passage through a column of Dowex AG-50 resin ( $\mathrm{H}^{+}$form; 200-400 mesh), the column being washed with $50 \%$ aq. methanol (v/v). The effluent and washings were combined, evaporated below $25^{\circ} \mathrm{C}$ and the residue was applied to Whatman no. 1 filter paper for chromatography in solvent 2 . After development for $14 \mathrm{~h}$, the chromatogram was cut horizontally into $1 \mathrm{~cm}$ strips and the radioactivity was determined by scintillation counting. Each radioactive acyl group was identified by comparison of its $\boldsymbol{R}_{\boldsymbol{F}}$ with that of the authentic acyl hydroxamate. Paper chromatography of $N$-hydroxysuccinamic acid in solvent 2 usually gave two radioactive components, the ratios of which were variable. For this study, we have assumed them to be isomeric forms of the same substance.

\section{Results}

\section{Pattern of labelling with different acyl groups}

Acetate. Three separate cultures of $M$. phlei cells, grown for (A) $20 \mathrm{~h}$, (B) $48 \mathrm{~h}$, and (C) $20 \mathrm{~h}$ with $0.2 \%$ Tween 80 , were incubated in the presence of sodium $\left[1{ }^{14} \mathrm{C}\right.$ ]acetate $(147 \mu \mathrm{Ci}, 2.6 \mu \mathrm{mol})$ at $30^{\circ} \mathrm{C}$ for $2 \mathrm{~h}$. Radioactive methylglucose-containing lipopolysaccharide was extracted and isolated as described in
'Methods'. Typical chromatographic patterns of the separations are shown in Figs. $2 a, b$ and $c$. The peaks of radioactivity and carbohydrate in Fig. $2 c$ correspond exactly, showing incorporation of radioactivity into fractions MGLP-I, -II, -III and -IV, although the amount in fraction MGLP-IV was too small for acyl group analysis. Specific radioactivities are listed in Table 1, and incorporation of radioactivity in total methylglucose-containing lipopolysaccharide varied from 0.05 to $0.1 \%$. In this particular study, MGLPIII was lacking in experiment $A$, while it was obtained in significant amount in experiments B and C. Thus, while fractions MGLP-I and MGLP-II were uniformly present, fractions MGLP-III and MGLP-IV were not always observed in a particular incubation.

Paper chromatograms of the acyl hydroxamates of the methylglucose-containing lipopolysaccharide fractions from experiment B are shown in Fig. 3, and the labelling patterns of the acyl groups of all three experiments are given in Table 1. The presence of Tween 20 decreased the amount of incorporation and changed the distribution of ${ }^{14} \mathrm{C}$ among the different acyl groups.

Propionate. Sodium $\left[1-{ }^{14} \mathrm{C}\right]$ propionate $(150 \mu \mathrm{Ci}$, $50 \mu \mathrm{mol}$ ) was added to a suspension of cells cultured for $48 \mathrm{~h}$, which was then incubated for $2.5 \mathrm{~h}$. The radioactivity incorporated into the methylglucose-containing lipopolysaccharide amounted to $0.063 \%$ and the specific radioactivity $\left(10^{-4} \times\right.$ c.p.m. $)$ of each species was I, 3.5; II, 2.5; III, 2.1; IV, 1.8. All of the radioactivity was found in the propionyl $(65 \%)$ and succinyl groups (35\%) (Fig. $4 a$ ).

Isobutyrate. Sodium $\left[1{ }^{14} \mathrm{C}\right]$ isobutyrate $(100 \mu \mathrm{Ci}$, $13.3 \mu \mathrm{mol}$ ) was incubated with cells grown for $20 \mathrm{~h}$. The DEAE-Sephadex pattern, which was similar to Fig. $2 c$, showed a relatively small amount of fraction MGLP-II and no fraction MGLP-IV. The specific radioactivities $\left(10^{-5} \times\right.$ c.p.m.) were I, 6.9; II, 8.2; III,

Table 1. Labelling pattern of acyl groups of methylglucose-containing lipopolysaccharide species isolated from cells after incubation with $\left[1-{ }^{14}\right.$ C]acetate

For details see the text.

$10^{-3} \times$ Specific radioactivity of acyl groups (c.p.m. $\left./ \mu \mathrm{mol}\right)$

\begin{tabular}{llccccc}
\multicolumn{1}{c}{ Experiment } & Fraction & Succinate & Acetate & Propionate & Isobutyrate & Octanoate \\
(A) & MGLP-I & 0 & 16.9 & 1.8 & 7.3 & 1.3 \\
20h culture & MGLP-II & 33.9 & 14.5 & 1.7 & 5.8 & 2.9 \\
(B) & MGLP-I & 0 & 16.3 & 1.2 & 2.3 & 5.8 \\
48h culture & MGLP-II & 18.9 & 9.4 & 1.8 & 1.3 & 0.8 \\
& MGLP-III & 11.2 & 8.3 & 2.8 & 1.1 & 0.3 \\
(C) & MGLP-I & 0 & 13.9 & 1.5 & 2.6 & 0.7 \\
20h culture & MGLP-II & 6.9 & 6.6 & 1.0 & 1.1 & 0.6 \\
with & MGLP-III & 4.1 & 6.3 & 0.5 & 0.5 & 0.3
\end{tabular}



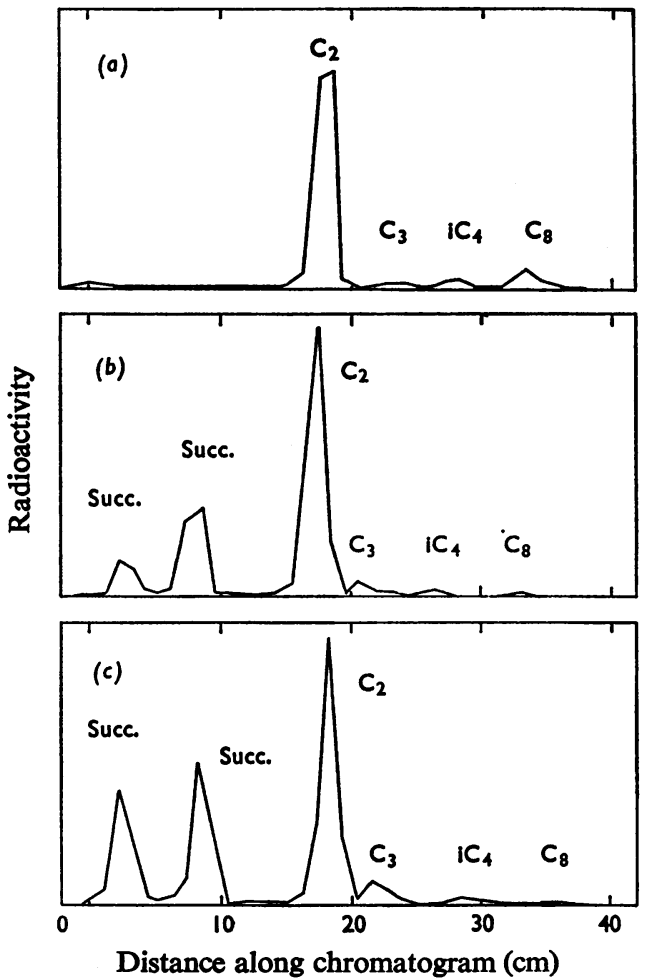

Fig. 3. Radioactivity profiles of paper chromatograms (solvent 2) of radioactive acyl hydroxamates of lipopolysaccharides

(a) MGLP-I, (b) MGLP-II, and (c) MGLP-III isolated from cells incubated with $\left[1-{ }^{14} \mathrm{C}\right] a c e t a t e$. The abbreviations are succinate (Succ.), acetate $\left(\mathrm{C}_{2}\right)$, propionate $\left(\mathrm{C}_{3}\right)$, isobutyrate $\left(\mathrm{iC}_{4}\right)$ and octanoate $\left(\mathrm{C}_{8}\right)$.

4.8. Most of the radioactivity was in isobutyrohydroxamate (Fig. $4 b$ ), but a trace was found as a component with chromatographic properties of octanohydroxamate. In other studies in this laboratory, a small amount of an acyl group with the properties of isooctanoate has been detected in methylglucose-containing lipopolysaccharide by $\mathrm{Dr}$. G. Gray (unpublished work).

n-Butyrate. Incorporation studies with sodium $n-\left[1-{ }^{14} \mathrm{C}\right]$ butyrate were carried out for $2 \mathrm{~h}$ with cells cultured for $20 \mathrm{~h}$. Radioactivity was recovered in all four lipopolysaccharide species. All of the radioactivity was found in $n$-butyrohydroxamate after the basic hydroxylamine treatment. This hydroxamate was eluted, hydrolysed and examined by gas-liquid chromatography. All of the radioactivity travelled with authentic $n$-butyric acid, and was clearly sepa-
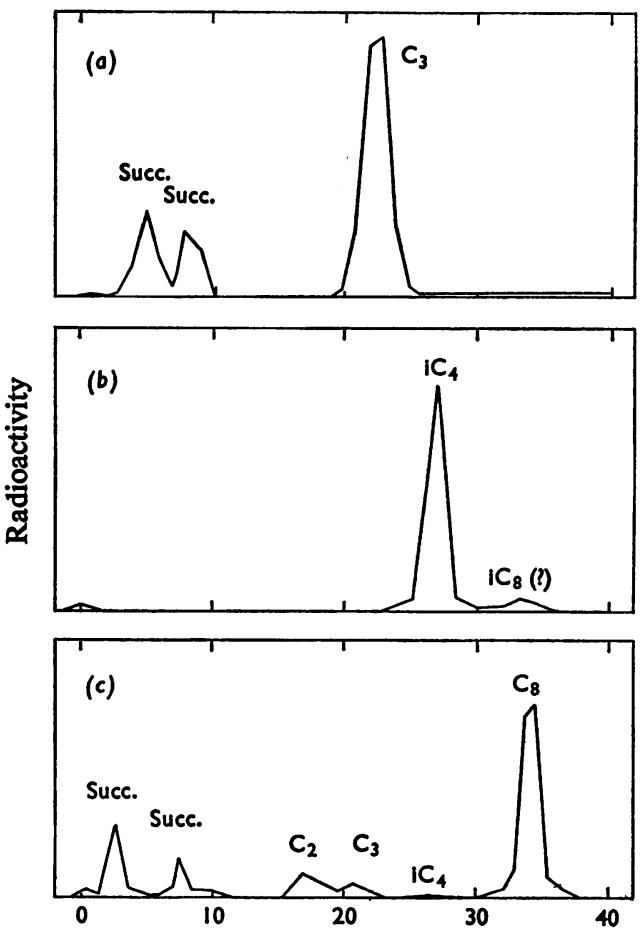

Distance along chromatogram (cm)

Fig. 4. Radioactivity profiles of paper chromatograms of radioactive acyl hydroxamates of lipopolysaccharide

(a) Lipopolysaccharides labelled by $\left[1-{ }^{14} \mathrm{C}\right]$ propionate; (b), MGLP-II labelled by $\left[1-{ }^{14} \mathrm{C}\right]$ isobutyrate; (c), methylglucose-containing lipopolysaccharide labelled by $\left[1-{ }^{14} \mathrm{C}\right]$ octanoate. The conditions and abbreviations are as in Fig. 3, with the addition of iso-octanoate $\left(\mathrm{iC}_{8}\right)$.

rated from isobutyrate (Fig. 5a). Similar treatment of the isobutyrohydroxamate, obtained from lipopolysaccharide in the incubation with $\left[{ }^{14} \mathrm{C}\right]$ isobutyrate, gave the pattern in Fig. $5 b$.

Hexanoate. Sodium $\left[1-{ }^{14} \mathrm{C}\right]$ hexanoate was incubated for $2 \mathrm{~h}$ with cells cultured for $20 \mathrm{~h}$. Radioactive hydroxamates, obtained from the crude methylglucose-containing lipopolysaccharide fraction, included those derived from acetate, succinate and octanoate. The material identified as octanohydroxamate was eluted and chromatographed in solvent 3. Although most of the radioactivity migrated with octanoic acid, a small amount was present in hexanoate.

Octanoate. Cells from a $20 \mathrm{~h}$ culture were incubated with sodium $\left[1-{ }^{14} \mathrm{C}\right]$ octanoate for $2 \mathrm{~h}$. Radioactivity

Vol. 132 

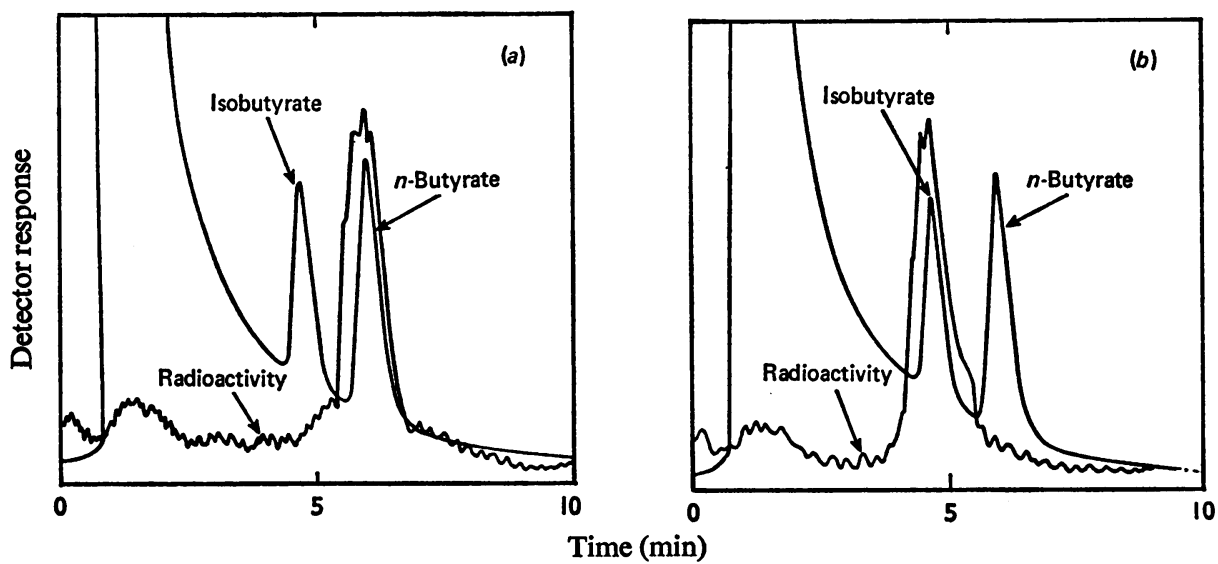

Fig. 5. Gas-liquid-chromatographic analysis of methylglucose-containing lipopolysaccharide acyl groups labelled by $\left(\right.$ a) $n-\left[1-{ }^{14} C\right]$ butyrate and $(b)\left[1-{ }^{14} C\right]$ isobutyrate

The jagged line represents radioactivity measured with a Nuclear-Chicago gas-flow counter. The solid line represents the added carrier fatty acid determined with the thermal conductivity detector in the Varian Autoprep. The Figures were redrawn to eliminate the time-lag between the radioactive peaks and carrier peaks resulting from the physical separation of the thermal conductivity detector and radio-detector.

was incorporated into all methylglucose-containing lipopolysaccharide species, and was found in all of the acyl groups of fraction MGLP-I. The radioactive hydroxamates derived from fraction MGLP-II were similar, except that some label was also found in the $N$-hydroxysuccinamic acid region of the chromatogram. A paper chromatogram of the acylhydroxamates of the total fraction is shown in Fig. $4 c$.

\section{Kinetic studies of fatty acid labelling}

Acetate. Cells grown for $20 \mathrm{~h}(6 \mathrm{~g})$ were suspended in $50 \mathrm{ml}$ of fresh medium and incubated in the presence of sodium $\left[1{ }^{14} \mathrm{C}\right]$ acetate $(100 \mu \mathrm{Ci}, 1.8 \mu \mathrm{mol})$. Samples $(8 \mathrm{ml})$ were removed from the flask after various times up to $4 \mathrm{~h}$ of incubation. Cells were collected by centrifugation and radioactivity in the supernatant was determined. The methylglucosecontaining lipopolysaccharide fraction, eluted from the Sephadex G-50 column, was re-extracted in chloroform-methanol $(2: 1, \mathrm{v} / \mathrm{v})$, and the extract was applied to a column of DEAE-Sephadex A-25 $\left(\mathrm{HCO}_{3}{ }^{-}\right)$at $4^{\circ} \mathrm{C}$. After washing the column with water, the methylglucose-containing lipopolysaccharide material was eluted with $0.15 \mathrm{M}-$ $\mathrm{NH}_{4} \mathrm{HCO}_{3}$. The removal of radioactivity from the medium and its appearance in the lipopolysaccharide are shown in Fig. 6(a), and the kinetics of labelling of the acyl groups are given in Fig. $6(b)$. The initial radioactivity was mainly in succinyl and octanoyl groups. After the initial high value, the specific radioactivity of the succinyl group decreased to a plateau value, but that of the octanoyl group remained essentially constant. The specific radioactivity in the acetyl group increased more slowly. Propionate and isobutyrate contained only small amounts of radioactivity, which reached maximum values at the same time as that of acetate.

Propionate. About $7 \mathrm{~g}$ of cells grown for $20 \mathrm{~h}$ were suspended in $50 \mathrm{ml}$ of fresh medium and incubated in the presence of sodium $\left[1-{ }^{14} \mathrm{C}\right]$ propionate $(100 \mu \mathrm{Ci}$, $33 \mu \mathrm{mol})$. Samples $(8 \mathrm{ml})$ were removed from the flask after various times up to $150 \mathrm{~min}$. Radioactivity in the medium decreased rapidly and the specific radioactivity of methylglucose-containing lipopolysaccharide attained a maximum at $50 \mathrm{~min}$ and then gradually decreased (Fig. 7a). The radioactivity of propionyl and succinyl groups reached maximum values during the first $30 \mathrm{~min}$ and then declined slowly in both (Fig. 7b).

Isobutyrate. From cells incubated in the presence of $\left[1-{ }^{14} \mathrm{C}\right]$ isobutyrate for various times up to $90 \mathrm{~min}$, the methylglucose-containing lipopolysaccharide was extracted and fractionated on a DEAE-Sephadex column. Radioactivity in the incubation medium decreased slowly, while the specific radioactivity of the lipopolysaccharide increased for $1 \mathrm{~h}$ and then remained constant. Almost $90 \%$ of the radioactivity was in the isobutyryl group even after $2 \mathrm{~h}$ of incubation. 

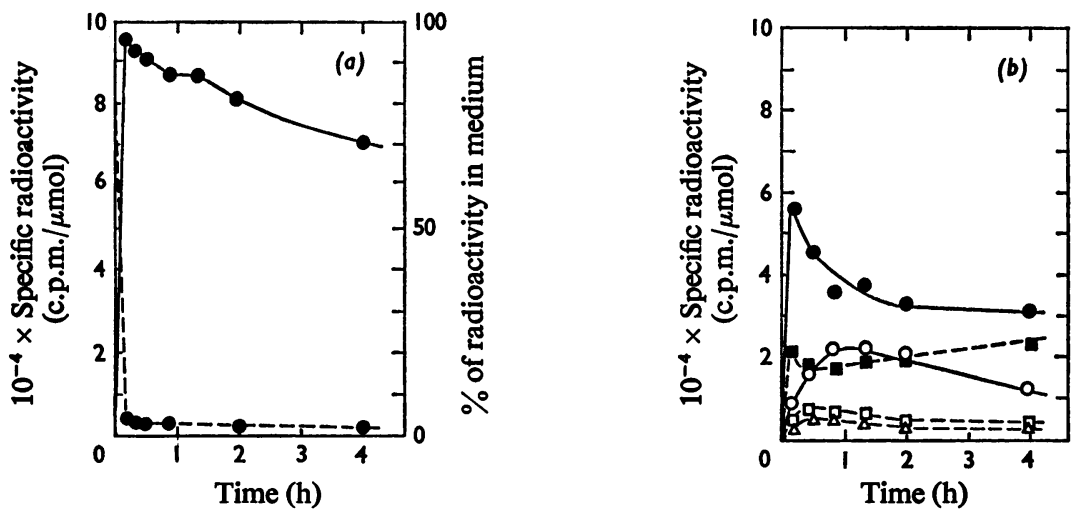

Fig. 6. Time-course of labelling of acyl groups of methylglucose-containing lipopolysaccharide by $\left[1-{ }^{14} \mathrm{C}\right]$ acetate

(a) Specific radioactivity of lipopolysaccharide (-); percentage of radioactivity remaining in incubation medium (---). (b), Radioactivity of acyl groups: succinate, $\bullet$; acetate, $\circ$; propionate, $\square$; isobutyrate, $\Delta$; octanoate, $\mathbf{\square}$.
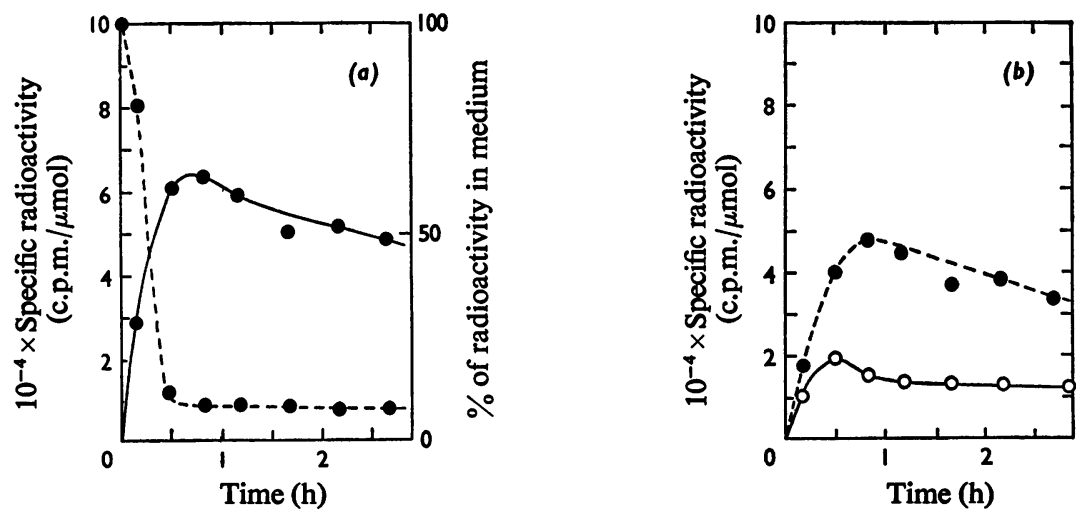

Fig. 7. Time-course of labelling of acyl groups of methylglucose-containing lipopolysaccharide by $\left[1-{ }^{14} \mathrm{C}\right]$ propionate

(a) Specific radioactivity of lipopolysaccharide (-); percentage of radioactivity remaining in incubation medium (---). (b) Radioactivity in propionate (o) and in succinate (๑).

Turnover of ${ }^{14} \mathrm{C}$-labelled acyl groups in methylglucosecontaining lipopolysaccharide

Acetate. Cells $(22 \mathrm{~g})$, grown for $20 \mathrm{~h}$ with $0.2 \%$ Tween 80 in the medium, were resuspended in $250 \mathrm{ml}$ of the same medium and incubated with sodium $\left[1-{ }^{14} \mathrm{C}\right]$ acetate $(500 \mu \mathrm{Ci}, 8.8 \mu \mathrm{mol})$ at $30^{\circ} \mathrm{C}$ for $2 \mathrm{~h}$. After that time, $50 \mathrm{ml}$ of the suspension was removed (fraction A) and the remainder was divided into two equal parts. To one was added sodium acetate and to the other sodium succinate, each in amount 1000 times that of the radioactive substance originally present. After $1.5 \mathrm{~h}$ of further incubation, half of each suspension was removed to give fractions $B$ and $D$, respectively. The remainder was incubated for $1.5 \mathrm{~h}$ more and the cells were harvested to give fractions $\mathrm{C}$ and E. From all five fractions methylglucosecontaining lipopolysaccharide was extracted and fractionated by DEAE-Sephadex column chromatography. Fraction $\mathbf{D}$ was omitted from the data for acyl group analysis because a large amount of an unknown radioactive substance contaminated it. The MGLP-I fraction of fraction $\mathrm{E}$ was also omitted 
Table 2. Turnover of labelled acyl groups in methylglucose-containing lipopolysaccharide of cells incubated with $\left[1-{ }^{14} \mathrm{C}\right]$ acetate

Expt. A was after $2 \mathrm{~h}$ of incorporation with labelled acetate, Expt. B after a $1.5 \mathrm{~h}$ 'chase' with unlabelled acetate, Expt. C after a $3 \mathrm{~h}$ 'chase' with unlabelled acetate and Expt. E after a $3 \mathrm{~h}$ 'chase' with unlabelled succinate.

$10^{-3} \times$ Specific radioactivity (c.p.m.)

\begin{tabular}{rlcccccc} 
& & \multicolumn{5}{c}{ Of acyl groups } \\
Expt. & Fraction & $\begin{array}{c}\text { Of MGLP } \\
\text { fractions }\end{array}$ & Succinate & Acetate & Propionate & Isobutyrate & Octanoate \\
(A) & MGLP-I & 85.9 & 0 & 23.6 & 5.4 & 8.0 & 1.7 \\
& MGLP-II & 62.9 & 17.1 & 13.3 & 3.1 & 2.6 & 2.8 \\
& MGLP-III & 49.3 & 10.8 & 5.8 & 4.1 & 4.4 & 1.8 \\
& MGLP-IV & 46.3 & 6.5 & 4.9 & 5.8 & 4.1 & 2.2 \\
(B) & MGLP-I & 38.2 & 0 & 6.9 & 2.7 & 10.2 & 4.5 \\
& MGLP-II & 42.6 & 18.4 & 5.9 & 2.3 & 2.5 & 1.8 \\
& MGLP-III & 46.5 & 3.8 & 2.0 & & 7.0 & 1.8 \\
& MGLP-IV & 55.4 & 10.7 & 4.1 & 6.2 & 2.7 & 2.2 \\
(C) & MGLP-I & 41.0 & 0 & 1.6 & 4.7 & 29.3 & 2.4 \\
& MGLP-II & 42.5 & 25.4 & 4.8 & 1.2 & 1.4 & 0.2 \\
& MGLP-III & 45.5 & 16.8 & 2.0 & 4.0 & 1.5 & 0.3 \\
& MGLP-IV & 46.8 & 9.4 & 2.5 & 5.6 & 2.3 & 3.2 \\
(E) & MGLP-I & 80.3 & & & & & \\
& MGLP-II & 91.1 & 66.2 & 4.1 & 8.3 & 3.4 & 1.8 \\
& MGLP-III & 97.2 & 42.4 & 1.4 & 6.1 & 1.6 & 0.6 \\
& MGLP-IV & 104.9 & 29.9 & 1.4 & 5.6 & 2.5 & 3.0 \\
& & & & & & & \\
\hline
\end{tabular}

from the analysis because it was contaminated with radioactive succinate originating from a succinylated polymannoside.

Specific radioactivities of the methylglucose-containing lipopolysaccharide fractions and their acyl groups are given in Table 2. Displacement of the radioactive acyl groups with unlabelled acetate is illustrated in Fig. 8. After the $3 \mathrm{~h}$ incubation, the specific radioactivity of acetyl groups in the different lipopolysaccharide fractions decreased by the following amount; MGLP-I (92\%), MGLP-II (64\%), MGLP-III (65\%) and MGLP-IV (49\%). The specific radioactivity in the succinyl group in all methylglucose-containing lipopolysaccharide species was higher after the 'chase' than at the beginning.

Propionate. About $26 \mathrm{~g}$ of cells grown for $20 \mathrm{~h}$ were resuspended in $150 \mathrm{ml}$ of medium and incubated with sodium $\left[1-{ }^{14} \mathrm{C}\right]$ propionate $(115 \mu \mathrm{Ci}, 38 \mu \mathrm{mol})$. After $1.5 \mathrm{~h}, 5 \mathrm{ml}$ was removed from the flask, and the remainder was incubated for $1 \mathrm{~h}$. After that, the cells were centrifuged, washed with medium and resuspended in $150 \mathrm{ml}$ of fresh medium, and two portions, one of $40 \mathrm{ml}$ and one of $5 \mathrm{ml}$ were reserved from the suspension. The remainder was divided in two equal parts, to one of which was added sodium propionate and to the other sodium succinate, each in amount 100 times that of radioactive substance originally present during the incorporation reaction.
After $2 \mathrm{~h}$, a $5 \mathrm{ml}$ portion of each suspension was removed. The remainder was incubated for $2 \mathrm{~h}$ longer, after which each was divided into a $40 \mathrm{ml}$ and a $5 \mathrm{ml}$ portion. Each of the $5 \mathrm{ml}$ portions was treated for the isolation of methylglucose-containing lipopolysaccharide and determination of its specific radioactivity. The three $40 \mathrm{ml}$ portions were used for the isolation of fraction MGLP-II and determination of the specific radioactivity of each acyl group. The changes in the specific radioactivity of the methylglucose-containing lipopolysaccharide are summarized in Fig. 9. The specific radioactivity of the succinyl group of fraction MGLP-II, which was originally $2.4 \times 10^{4} \mathrm{c} . \mathrm{p} . \mathrm{m} . / \mu \mathrm{mol}$, decreased $57 \%$ after incubation with unlabelled sodium succinate and $33 \%$ after incubation with unlabelled sodium propionate. The radioactivity of the propionyl group of fraction MGLP-II $\left(1.4 \times 10^{4}\right.$ c.p.m.) decreased $45 \%$ after incubation with unlabelled sodium propionate and $54 \%$ after incubation with unlabelled sodium succinate. From these results it seems that the specific radioactivity of methylglucose-containing lipopolysaccharide, which was already decreasing because of the prolonged incubation, was not affected by the addition of unlabelled propionate or succinate to the medium. Moreover, there was no significant difference in the ability of unlabelled succinate and propionate to displace the labelled 


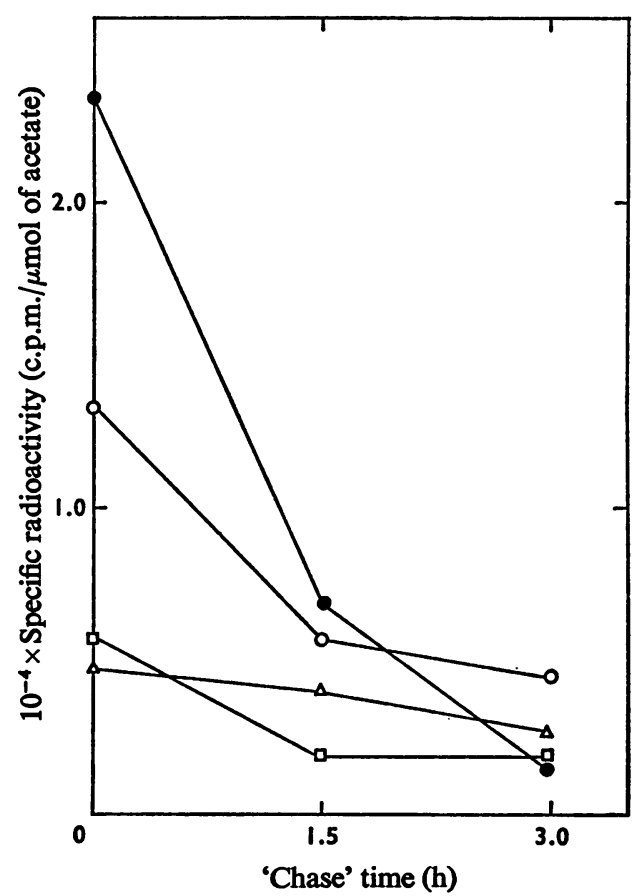

Fig. 8. Displacement of the $\left[{ }^{14} \mathrm{C}\right]$ acetyl group of methylglucose-containing lipopolysaccharide by unlabelled acetate

This Figure was plotted from some of the results of Table 2. Fractions: MGLP-I, •; MGLP-II, o; MGLP-III, $\square$; MGLP-IV, $\Delta$.

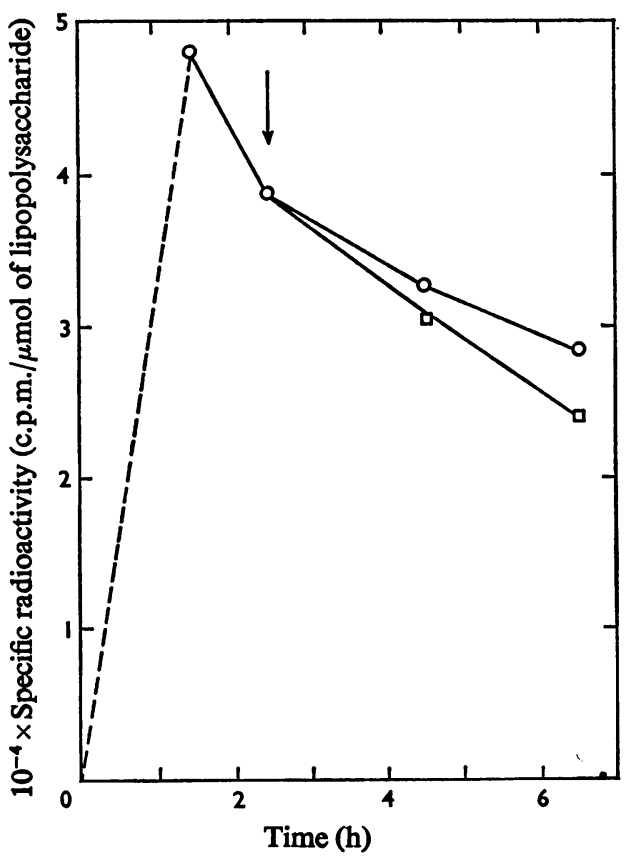

Fig. 9. Displacement of $\left[{ }^{14} \mathrm{C}\right]$ propionyl and $\left[{ }^{14} \mathrm{C}\right]-$ succinyl groups of methylglucose-containing lipopolysaccharides after labelling with $\left[1-{ }^{14} \mathrm{C}\right]$ propionate

The arrow indicates the point at which unlabelled propionate $(0)$ and succinate $(\square)$ were added.

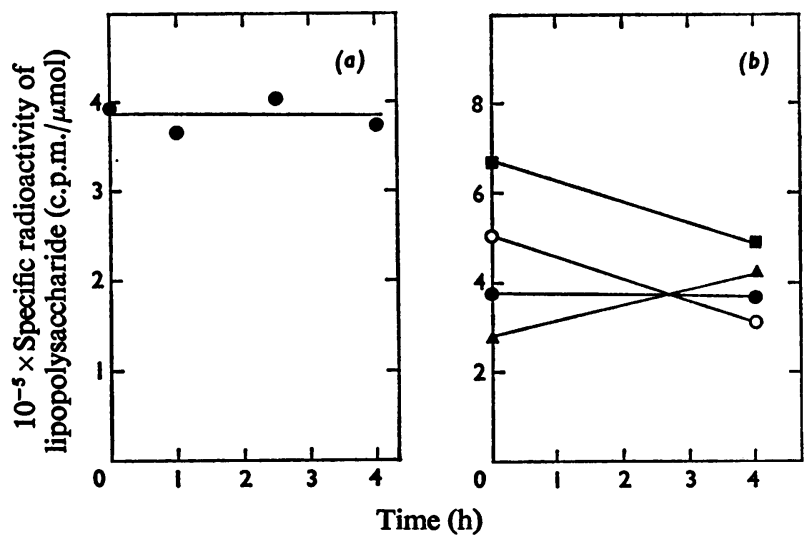

Fig. 10. Turnover of the $\left[{ }^{14} \mathrm{C}\right]$ isobutyryl group of the lipopolysaccharides

(a) Specific radioactivity of the total methylglucose-containing lipopolysaccharide at various times after addition of unlabelled isobutyrate; $(b)$ specific radioactivity of isobutyryl groups at various times after addition of

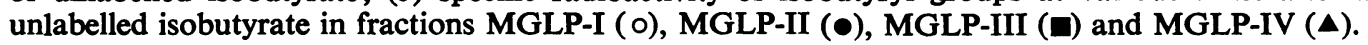

Vol. 132 
propionyl group. It may be significant that the labelled succinyl group derived from propionate was displaced by the incubation with unlabelled succinate; whereas this same acyl group, derived from acetate, increased in specific radioactivity during the 'chase' experiment described in Table 2. are found in all forms of methylglucose-containing lipopolysaccharide, to be added to the methylglucose-containing polysaccharide (MGP) before the stepwise addition of succinate, leading to the formation of fractions MGLP-II, -III and -IV, according to the following scheme:

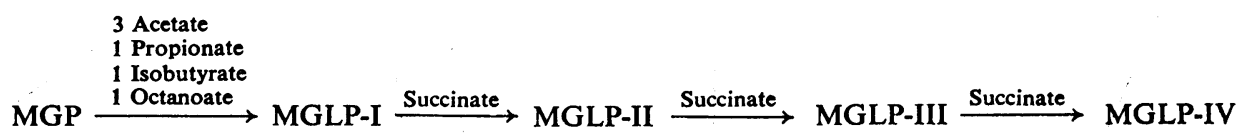

Isobutyrate. Cells grown for $20 \mathrm{~h}$ were suspended in $100 \mathrm{ml}$ of medium and incubated with sodium $\left[1-{ }^{14} \mathrm{C}\right]$ isobutyrate $(50 \mu \mathrm{Ci}, 6.7 \mu \mathrm{mol})$ for $2 \mathrm{~h}$. After incubation, the cells were collected by centrifugation, washed with fresh medium and resuspended in $100 \mathrm{ml}$ of medium. A sample of this suspension was reserved for analysis. To the remainder, sodium isobutyrate in amount 100 times that of the radioactive substanee was added and the incubation was continued. After various times, samples were removed for the extraction of methylglucose-containing lipopolysaccharide and determination of its specific radioactivity. From the results given in Fig. 10(a) it appears that the isobutyryl group of the total methylglucosecontaining lipopolysaccharide did not turn over. Analysis of the individual lipopolysaccharide species, however, revealed a complicated relationship (Fig. $10 b$ ), which indicated that the isobutyryl group of each lipopolysaccharide species did change slightly and in an independent fashion.

\section{Discussion}

One aim of this investigation was to determine whether the Mycobacterium phlei methylglucose lipopolysaccharide served as an acyl carrier for the biosynthesis of other fatty acids. This would have been implied by a rapid turnover of the acyl groups in the lipopolysaccharide as measured by the incorporation and 'chase' of $\left[{ }^{14} \mathrm{C}\right] \mathrm{acyl}$ groups. While all of the fatty acids normally found in the methylglucose-containing lipopolysaccharide were readily incorporated by whole cells into the different lipopolysaccharide species, not all of them appeared to exchange under the conditions of the experiments. Once incorporated into the lipopolysaccharide, $\left[{ }^{14} \mathrm{C}\right]$ acetate was the most readily displaced of the acyl groups, while $\left[{ }^{14} \mathrm{C}\right]$ isobutyrate showed no net loss during a $4 \mathrm{~h}$ incubation after addition of the unlabelled fatty acid.

A second aim of the study was to determine whether there was an ordered manner in which the acyl groups were incorporated into the lipopolysaccharide species. As a working hypothesis, it would seem reasonable to expect the $6 \mathrm{~mol}$ of monocarboxylic acids, which
The kinetic study of the incorporation and turnover of $\left[{ }^{14} \mathrm{C}\right]$ acetate in the various lipopolysaccharide species was consistent with this pathway (Fig. 8). After the initial incubation, the specific radioactivities of the acetyl groups decreased in the order MGLP-I > MGLP-II > MGLP-III; while, after the 'chase', the radioactivity in fraction MGLP-I had decreased precipitously, the radioactivity in fraction MGLP-II was decreased by about $60 \%$, and that of fraction MGLP-III was only slightly decreased. On the other hand, the turnover of $\left[{ }^{14} \mathrm{C}\right]$ isobutyrate was inconsistent with such a scheme; once this fatty acid became incorporated into the different methylglucosecontaining lipopolysaccharide species, it did not show any appreciable change on further incubation in the presence of unlabelled isobutyrate. Thus, we have to conclude that, while the above scheme may represent the pathway of synthesis de novo, the further independent metabolism of the individual acyl groups may modify the labelling pattern that would have been expected. The observation that the acetyl group appeared to be in a rapid state of flux, while the isobutyryl group was retained once it was esterified into the lipopolysaccharide, is consistent with this conclusion.

While the propionyl group paralleled isobutyrate in its metabolic activity, succinate showed a more complicated metabolism which depended on whether this acyl group was derived from $\left[{ }^{14} \mathrm{C}\right]$ acetate or from $\left[{ }^{14} \mathrm{C}\right]$ propionate. In the former case, the specific radioactivity of the succinate in the lipopolysaccharide was considerably higher than that of the acetate (Fig. $6 b$ ), even though the succinyl-CoA formed from the acetate must have been diluted by endogenous intermediates. Apparently, most of the labelled acetate was directed into the tricarboxylic acid cycle, resulting in the formation of succinyl-CoA of high specific radioactivity. Moreover, the succinate group incorporated into the methylglucose-containing lipopolysaccharide from this source was not actively metabolized (Table 2). On the other hand, labelled succinate derived from $\left[{ }^{14} \mathrm{C}\right]$ propionate appeared to turn over more readily. This difference could be explained if the succinyl-CoA from the two different 
sources were compartmentalized and were utilized for the acylation of different positions in the lipopolysaccharide molecule. It is reasonable to postulate that the succinyl group in different positions in the lipopolysaccharide may turn over at different rates. The labelling of the succinyl groups, which was observed with $\left[{ }^{14} \mathrm{C}\right]$ propionate as the precursor, presumably occurred by the action of propionyl-CoA carboxylase and methylmalonyl-CoA mutase, both of which have been reported in Mycobacterium species (Stjernholm et al., 1962).

Obviously, some factor controls the lipopolysaccharide composition, since all four forms of methylglucose-containing lipopolysaccharide were not uniformly observed in a particular culture. While fractions MGLP-I and -II were always obtained in the extracts, fractions MGLP-III and -IV were variable in their presence. Since forms II, III and IV depend on the succinylation reaction, the observed variability must reflect a control of this acylation step.

Succinylated polysaccharides in $M$. phlei are not limited to methylglucose-containing lipopolysaccharide. As mentioned above, succinylated polymannosides were occasionally encountered as minor contaminants in all methylglucose-containing lipopolysaccharide species. They appeared in much larger amount, together with succinylated arabinomannans, in the supernatant fraction of cells disrupted by sonic oscillation, suggesting that they may be derived from the cell wall or membrane.

The incorporation of $\left[{ }^{14} \mathrm{C}\right]$ isobutyrate into the methylglucose-containing lipopolysaccharide was quite efficient, perhaps because of the more limited pathways for the utilization of this fatty acid. Although most of the incorporated label was recovered as isobutyrate, a small amount was found in iso- octanoate. This is in contrast to the report that Mycobacterium tuberculosis is unable to synthesize longer iso fatty acids from isobutyrate (Asselineau, 1966).

When supplied in the medium, $n-\left[{ }^{14} \mathrm{C}\right]$ butyrate and $\left[{ }^{14} \mathrm{C}\right]$ hexanoate were incorporated as such into the methylglucose-containing lipopolysaccharide even though these acyl groups are not found as normal components of the lipopolysaccharide. This could reflect a broad specificity in the acyl transferases that are involved in synthesis of the methylglucosecontaining lipopolysaccharide. On the other hand, the fact that these acyl groups are not found in these lipopolysaccharides may mean that $n$-butyryl-CoA and hexanoyl-CoA are not normally available in the cell at the site of lipopolysaccharide acylation. This explanation raises the interesting question as to why octanoate is a normal component of these lipopolysaccharides.

Ilton et al. (1971) reported that 6-O-methylglucosecontaining lipopolysaccharides and a 3-O-methylmannose-containing polysaccharide, probably the same substances studied in this laboratory (Ballou, 1968; Gray \& Ballou, 1971), stimulate the fatty acid synthetase of $M$. phlei. This finding is interesting because these substances have an amphipathic nature which could promote their interaction with the multi-enzyme complex of the synthetase system. In particular, it is tempting to speculate that the lipopolysaccharide may function as a regulator of fatty acid metabolism by virtue of its multiple forms and varied precursors. These relationships are shown in Scheme 1. The methyl groups in the methylglucosecontaining lipopolysaccharide are derived from $S$ adenosylmethionine, and a polysaccharide methyltransferase of appropriate specificity has been isolated from M. phlei (Ferguson \& Ballou, 1970; Grellert \&

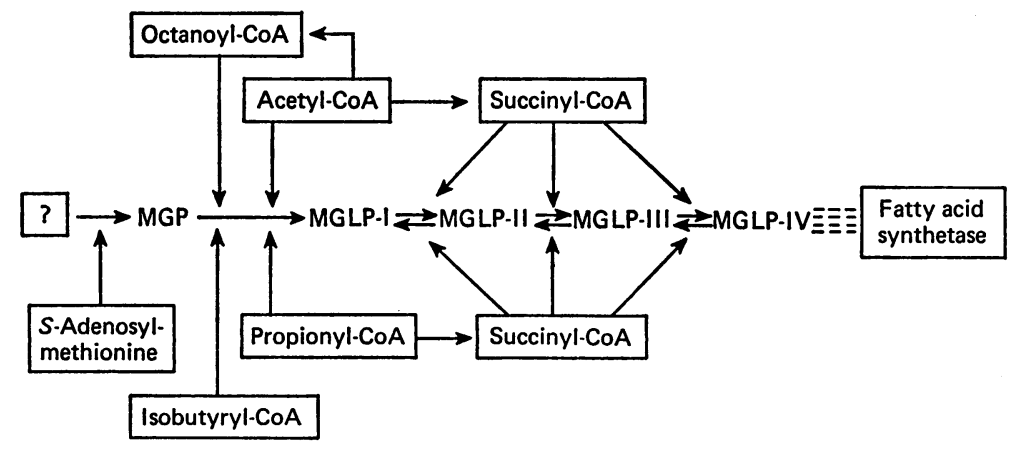

Scheme 1. Possible relationships of the methylglucose-containing lipopolyscacharide as a regulator of fatty acid metabolism in mycobacteria

For details see the Discussion section. Abbreviation: MGP, methylglucose-containing polysaccharide.

Vol. 132 
Ballou, 1972). We have found that acetyl-CoA can function as an acyl group donor for methylglucosecontaining lipopolysaccharide biosynthesis with a cell-free system from $M$. phlei (J. Tung \& C. E. Ballou, unpublished work). All of the acyl-CoA derivatives could originate by oxidative degradation of fatty acids, and their acyl groups may be transferred to the polysaccharide backbone by specific acyltransferases. While Scheme 1 suggests that the monocarboxylic acids are added to methylglucosecontaining polysaccharides to form fraction MGLP-I before succinylation occurs, our studies suggest that some of these acyl groups are added or exchanged after succinylation. Nor can we rule out the possibility that some acylation occurs before methylation, since the endogenous methyl acceptor has not been identified. We conclude from the present study that each acyl group of each methylglucose-containing lipopolysaccharide species has its own rate of turnover, which may be controlled by the nutritional state of the cell. Growing cells, with a high rate of respiration, could generate the organic acids for biosynthesis of the acyl groups of the methylglucosecontaining lipopolysaccharide. The lipopolysaccharide thus synthesized could regulate the fatty acid synthetase (Ilton et al., 1971) and perhaps supply acyl groups for the biosynthesis of other fatty acids. While it is possible that the methylglucose-containing lipopolysaccharide may function as an 'acyl-carrier polysaccharide', we envisage a more fundamental role in which the concentrations of the various methylglucose-containing lipopolysaccharide species would serve as a reflection of the pool sizes of the individual acyl-CoA precursors.

This work was supported by Public Health Service Grant AM-884 and National Science Foundation Grant GB-7427. Some preliminary experiments related to this study were conducted by Mr. J. C. Unkeless.

\section{References}

Asselineau, J. (1966) in The Bacterial Lipids (Asselineau, J., ed.), p. 146, Holden-Day Inc., San Francisco

Ballou, C. E. (1968) Accounts Chem. Res. 11, 366-373

Bray, G. A. (1960) Anal. Biochem. 1, 279-285

Brennan, P. \& Ballou, C. E. (1967) J. Biol. Chem. 242, 3046-3056

Ferguson, J. A. \& Ballou, C. E. (1970) J. Biol. Chem. 245, 4213-4223

Gray, G. R. \& Ballou, C. E. (1971) J. Biol. Chem. 246, 6835-6842

Grellert, E. A. \& Ballou, C. E. (1972) J. Biol. Chem. 247, 3236-3241

Ilton, M., Jevans, A. W., McCarthy, E. D., Vance, D. White, H. B., III \& Bloch, K. (1971) Proc. Nat. Acad. Sci. U.S. 68, 87-91

Keller, J. M. \& Ballou, C. E. (1968) J. Biol. Chem. 243, 2905-2910

Smith, F. \& Montgomery, R. (1956) Methods Biochem. Anal. 3, 153-212

Stjernholm, R. L., Noble, R. E. \& Koch-Weser, D. (1962) Biochim. Biophys. Acta 64, 174-177 